\title{
Copolymerization of New Styrene Derivatives Having Alkylamino Group: $p$-Diethylaminoethylstyrene, $m$-Diethyl- aminoethylstyrene and a Quaternized Derivative
}

\author{
Joei YuKawA, Kazunori KatAOKA, ${ }^{*}$ and Teiji TsurutA \\ Department of Synthetic Chemistry, Faculty of Engineering, \\ University of Tokyo, Hongo, Bunkyo-ku, Tokyo 113, Japan.
}

(Received July 19, 1979)

\begin{abstract}
The copolymerization behavior of new styrene derivatives, namely, $p$ diethylaminoethylstyrene ( $p$-EAS), $m$-diethylaminoethylstyrene ( $m$-EAS), and $p$-vinylphenethyltriethylammonium bromide( $p$-VPAB), was examined. Copolymerization parameters of $m$-EAS were similar to those of styrene or $m$-methylstyrene, and a significant effect of the diethylaminoethyl group was observed in $p$-EAS. $Q, e$-Values of $p$-EAS were very close to those of $p$-dimethylaminostyrene. When $P$-EAS was copolymerized with acrylamide (AAm) in methanol, $p$-EAS exhibited a greater reactivity than AAm, which may be explained as a possible effect of the $p$-EAS causing an increase in the equilibrated concentration of the less reactive isomeric form of AAm. In the copolymerization of cationic monomer, $p$-VPAB, with MMA, $p$-VPAB exhibited less reactivity than MMA, owing to Coulombic repulsion between $p$-VPAB and the growing chain-end.
\end{abstract}

KEY WORDS Copolymerization /New Monomers / $p$-Diethylaminoethylstyrene $/ m$-Diethylaminoethylstyrene $/ p$-Vinylphenethyltriethylammonium Bromide / Monomer Reactivity Ratios / $Q, e$-Values / Polyamines / Polycations / Functional Polymers /

As reported in a previous paper, ${ }^{1}$ the reaction of $p$ divinylbenzene ( $p$-DVB) and diethylamine catalyzed by lithium diethylamide gave $p$-diethylamino- ethylstyrene ( $p$-EAS) or 1,4-bis(2- diethylaminoethyl)benzene ( $p$-BEAB), selectively and quantitatively (see eq 1 and 2).

$$
\begin{aligned}
& \mathrm{CH}_{2}=\mathrm{CH}-\mathrm{O}-\mathrm{CH}=\mathrm{CH}_{2}+\mathrm{Et}_{2} \mathrm{NH} \stackrel{\mathrm{Et}_{2} \mathrm{NLi}}{\longrightarrow} \mathrm{CH}_{2}=\mathrm{CH}-\mathrm{O}-\mathrm{CH}_{2} \mathrm{CH}_{2} \mathrm{NEt}_{2} \\
& p \text {-DVB } \quad p \text {-EAS }
\end{aligned}
$$

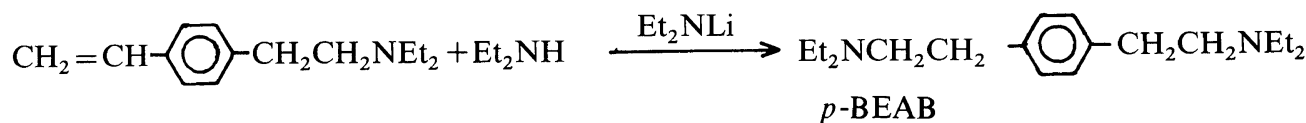

Similarly, $m$-diethylaminoethylstyrene and 1,3bis(2-diethylaminoethyl)benzene ( $m$-BEAB) were selectively synthesized from $m$-divinylbenzene. ${ }^{2}$

New polymers having alkylamino- or alkylammonio-substituents can be derived from EAS or

* Present address: Institute of Medical Engineering, Tokyo Women's Medical College, 10 Kawada-cho, Shinjuku-ku, Tokyo 162, Japan. its quaternized derivative as starting monomers. These polymers have properties expected to hold

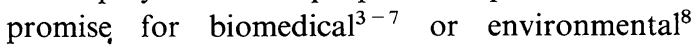
applications.

In this study, the copolymerization behavior of $p$ EAS, $m$-EAS, and $p$-vinylphenethyltriethylammonium bromide ( $p$-VPAS) was examined to obtain information useful for synthesizing a variety of copolymers having alkylamino groups. 


\section{J. Yukawa, K. Kataoka, and T. Tsuruta}

\section{EXPERIMENTAL}

\section{Materials}

The solvents were purified by conventional methods. Styrene was successively washed with an aqueous solution of sodium thiosulfate, dilute aqueous solution of sdoium hydroxide, and water; it was then dried over barium oxide, and distilled twice under reduced pressure. Methyl methacrylate (MMA) and ethyl acrylate were successively washed with a dilute aqueous solution of sodium sulfite, $5 \%$ aqueous solution of sodium hydroxide, and $2 \%$ aqueous solution of sodium chloride; they were dried over sodium sulfate, and distilled twice under reduced pressure. Acrylamide (AAm) was recrystallized from benzene, and dried in vacuo at room temperature. Azobisisobutyronitrile (AIBN) was recrystallized from ethanol and dried in vacuo at room temperature. Preparation of $p$-EAS, $m$-EAS, and $p$ VPAB was reported previously. ${ }^{1.2 .4}$

\section{Copolymerization Procedure}

A glass ampoule, which had been flushed with dry nitrogen, was charged with monomers, solvent, and initiator. The ampoule was sealed in vacuo. Polymerization was carried out at $60^{\circ} \mathrm{C}$. The copolymer was precipitated twice by a large excess of a non-solvent, and dried in vacuo at room temperature until a constant weight was reached. The freezedrying technique was also adopted in a certain series of experiments.

\section{Determination of Copolymer Composition}

Copolymer compositions were determined by analysis for nitrogen contents. In a certain series of experiments, ${ }^{1} \mathrm{H}$ NMR spectroscopy was also used for the determination of copolymer composition by comparison of the integral intensity of aliphatic and aromatic hydrogens. The Kelen-Tüdös method was used for the calculation of monomer reactivity ratios. ${ }^{9}$

\section{RESULTS}

\section{Determination of Monomer Reactivity Ratios}

The copolymerization results are listed in Tables

Table I. Copolymerization of $p$-diethylaminoethylstyrene ( $p$-EAS) $\left(\mathrm{M}_{1}\right)$ with MMA $\left(\mathrm{M}_{2}\right)$ in toluene at $60^{\circ} \mathrm{C}^{\mathrm{a}}$

\begin{tabular}{|c|c|c|c|c|c|c|}
\hline \multirow{2}{*}{ Run no. } & \multicolumn{2}{|c|}{ Amount of monomer feed } & \multirow{2}{*}{$\begin{array}{l}\mathrm{mol}^{\circ} \% \text { of } \mathrm{M}_{1} \text { in } \\
\text { monomer feed }\end{array}$} & \multirow{2}{*}{ Yield $^{\mathrm{b}} / \%$} & \multirow{2}{*}{$\mathrm{N} / \%$} & \multirow{2}{*}{$\begin{array}{l}\mathrm{mol}^{\%} \text { of } \mathrm{M} \\
\text { in polymer }\end{array}$} \\
\hline & $\mathrm{M}_{1} / \mathrm{mmol}$ & $\mathrm{M}_{2} / \mathrm{mmol}$ & & & & \\
\hline 1 & 1.90 & 8.02 & 19.2 & 2.0 & 3.39 & 32.3 \\
\hline 2 & 4.18 & 6.23 & 40.2 & 11.4 & 4.28 & 44.7 \\
\hline 3 & 5.58 & 7.29 & 44.5 & 12.6 & 4.31 & 45.1 \\
\hline 4 & 6.47 & 4.15 & 60.9 & 8.7 & 4.60 & 49.7 \\
\hline
\end{tabular}

a Toluene, $2 \mathrm{~cm}^{\dot{3}}$; AIBN, $0.02 \mathrm{mmol}$; polymerization time, $2 \mathrm{~h}$

b Petroleum ether-insoluble fraction at $-50^{\circ} \mathrm{C}$.

Table II. Copolymerization of $p$-EAS $\left(\mathrm{M}_{1}\right)$ with styrene $\left(\mathrm{M}_{2}\right)$ in toluene at $60^{\circ} \mathrm{C}^{\mathrm{a}}$

\begin{tabular}{|c|c|c|c|c|c|c|}
\hline \multirow{2}{*}{ Run no. } & \multicolumn{2}{|c|}{ Amount of monomer feed } & \multirow{2}{*}{$\begin{array}{l}\mathrm{mol}^{\%} \text { of } \mathrm{M}_{1} \text { in } \\
\text { monomer feed }\end{array}$} & \multirow{2}{*}{ Yield $/ \%$} & \multirow{2}{*}{$\mathrm{N} / \%$} & \multirow{2}{*}{$\begin{array}{c}\mathrm{mol}^{\circ} \% \text { of } \mathrm{M}_{1} \\
\text { in polymer }\end{array}$} \\
\hline & $\mathrm{M}_{1} / \mathrm{mmol}$ & $\mathrm{M}_{2} / \mathrm{mmol}$ & & & & \\
\hline 1 & 1.83 & 8.24 & 18.2 & 6.27 & 1.67 & $14.1(17.0$ \\
\hline 2 & 3.31 & 6.72 & 33.0 & 3.47 & 2.82 & $26.2(28.8)$ \\
\hline 3 & 4.24 & 6.32 & 40.2 & 4.01 & 3.41 & $33.4(36.3)$ \\
\hline 4 & 4.68 & 5.14 & 47.8 & 4.92 & 4.06 & $42.4(44.5)$ \\
\hline 5 & 7.80 & 2.26 & 77.5 & 6.46 & 5.52 & $67.4(70.8)$ \\
\hline
\end{tabular}

a Toluene, $3 \mathrm{~cm}^{3}$; AIBN, $0.02 \mathrm{mmol}$. Polymerization time: run 1, 2, and 3, $150 \mathrm{~min}$; run 4, $240 \mathrm{~min}$; run5, $270 \mathrm{~min}$.

b Petroleum ether-insoluble fraction at $-50^{\circ} \mathrm{C}$.

c Values designated in parentheses were evaluated from the ${ }^{1} \mathrm{H}$ NMR spectra of the copolymers. 
Copolymerization of New Monomers Having Amino Group

Table III. Copolymerization of $p$-EAS $\left(\mathrm{M}_{1}\right)$ with AAm $\left(\mathrm{M}_{2}\right)$ in methanol at $60^{\circ} \mathrm{C}^{\mathrm{a}}$

\begin{tabular}{|c|c|c|c|c|c|c|}
\hline \multirow{2}{*}{ Run no. } & \multicolumn{2}{|c|}{ Amount of monomer feed } & \multirow{2}{*}{$\begin{array}{c}\mathrm{mol}^{\circ} / \text { of } \mathrm{M}_{1} \text { in } \\
\text { monomer feed }\end{array}$} & \multirow{2}{*}{ Yield $^{\mathbf{b}} / \%$} & \multirow{2}{*}{$\mathrm{N} / \%$} & \multirow{2}{*}{$\begin{array}{c}\mathrm{mol}^{\circ} \% \text { of } \mathrm{M}_{1} \\
\text { in polymer }\end{array}$} \\
\hline & $\mathrm{M}_{1} / \mathrm{mmol}$ & $\mathrm{M}_{2} / \mathrm{mmol}$ & & & & \\
\hline 1 & 0.93 & 8.99 & 9.4 & 3.53 & 11.85 & 35.5 \\
\hline 2 & 1.81 & 8.21 & 18.1 & 11.6 & 9.93 & 53.0 \\
\hline 3 & 2.98 & 7.04 & 29.7 & 4.40 & 9.28 & 60.3 \\
\hline 4 & 4.29 & 5.93 & 42.0 & 9.19 & 8.48 & 71.3 \\
\hline 5 & 6.40 & 4.14 & 60.7 & 4.11 & 7.53 & 86.9 \\
\hline
\end{tabular}

a Methanol, $2 \mathrm{~cm}^{3}: \mathrm{AIBN}, 0.02 \mathrm{mmol}$; Polymerization time: run 1 and 3, $60 \mathrm{~min}$; run 2, $90 \mathrm{~min}$; run 4 and 5, $110 \mathrm{~min}$.

b Acetone-insoluble fraction at $-50^{\circ} \mathrm{C}$.

Table IV. Copolymerization of $p$-vinylphenethyltriethylammonium bromide $\left(p\right.$-VPAB) $\left(\mathrm{M}_{1}\right)$ with MMA $\left(\mathrm{M}_{2}\right)$ in methanol at $60^{\circ} \mathrm{C}^{\mathrm{a}}$

\begin{tabular}{|c|c|c|c|c|c|}
\hline \multirow{2}{*}{ Run no. } & \multicolumn{2}{|c|}{ Amount of monomer feed } & \multirow{2}{*}{$\begin{array}{l}\mathrm{mol}^{\%} \text { of } \mathrm{M}_{1} \text { in } \\
\text { monomer feed }\end{array}$} & \multirow{2}{*}{ Yield $1 \%$} & \multirow{2}{*}{$\begin{array}{l}\mathrm{mol}^{\circ} \% \text { of } \mathrm{M} \\
\text { in polymer }\end{array}$} \\
\hline & $\mathrm{M}_{1} / \mathrm{mmol}$ & $\mathrm{M}_{2} / \mathrm{mmol}$ & & & \\
\hline 1 & 2.72 & 6.72 & 28.8 & 10.33 & 23.4 \\
\hline 2 & 4.73 & 4.65 & 50.4 & 6.64 & 38.8 \\
\hline 3 & 5.15 & 3.72 & 58.1 & 6.23 & 41.9 \\
\hline 4 & 7.13 & 2.51 & 74.0 & 3.49 & 50.8 \\
\hline
\end{tabular}

a Methano1, $3 \mathrm{~cm}^{3}$ : AIBN, $0.02 \mathrm{mmol}$; polymerization time, $3 \mathrm{~h}$.

b Acetone-insoluble fraction at $-50^{\circ} \mathrm{C}$.

c Determined by means of ${ }^{1} \mathrm{H}$ NMR spectroscopy.

Table V. Copolymerization of $m$-diethylaminoethylstyrene $\left(m\right.$-EAS) $\left(\mathbf{M}_{1}\right)$ with MMA $\left(\mathrm{M}_{2}\right)$ in toluene at $60^{\circ} \mathrm{C}^{\mathrm{a}}$

\begin{tabular}{|c|c|c|c|c|c|c|}
\hline \multirow{2}{*}{ Run no. } & \multicolumn{2}{|c|}{ Amount of monomer feed } & \multirow{2}{*}{$\begin{array}{l}\mathrm{mol}^{\circ} / \mathrm{o} \text { of } \mathbf{M}_{1} \text { in } \\
\text { monomer feed }\end{array}$} & \multirow{2}{*}{ Yield $\mathbf{b} \%$} & \multirow{2}{*}{$\mathrm{N} / \%$} & \multirow{2}{*}{$\begin{array}{c}\mathrm{mol}^{\circ} \% \text { of } \mathbf{M}_{1} \\
\text { in polymer }\end{array}$} \\
\hline & $\mathrm{M}_{1} / \mathrm{mmol}$ & $\mathrm{M}_{2} / \mathrm{mmol}$ & & & & \\
\hline 1 & 1.87 & 8.23 & 18.5 & 2.76 & 2.94 & 26.8 \\
\hline 2 & 6.07 & 8.30 & 42.0 & 1.50 & 4.17 & 42.9 \\
\hline 3 & 5.49 & 5.71 & 49.0 & 16.60 & 4.52 & 48.3 \\
\hline 4 & 5.39 & 5.09 & 51.0 & 7.51 & 4.54 & 49.0 \\
\hline 5 & 6.27 & 3.98 & 61.2 & 5.29 & 5.02 & 57.0 \\
\hline 6 & 6.18 & 3.76 & 62.0 & 22.40 & 5.02 & 57.0 \\
\hline 7 & 7.96 & 2.75 & 74.3 & 2.59 & 5.55 & 67.2 \\
\hline
\end{tabular}

a Toluene, $3 \mathrm{~cm}^{3}$ : AIBN, $0.02 \mathrm{mmol}$. Polymerization time: run 1, 2, and 4, $240 \mathrm{~min}$; run 3 and 6, $360 \mathrm{~min}$; run 5 and 7 , $180 \mathrm{~min}$.

b Petroleum ether-insoluble fraction at $-50^{\circ} \mathrm{C}$.

I-VII.

As shown in Table VIII, the monomer reactivity ratios were calculated from the data listed in Tables I-VII by the method of Kelen and Tüdös. ${ }^{9}$
In Table IX are listed the Alfrey-Price $Q$ - and $e$ values for EAS and VPAB calculated from the monomer reactivity ratios. 
Table VI. Copolymerization of $m$-EAS $\left(\mathrm{M}_{1}\right)$ with styrene $\left(\mathrm{M}_{2}\right)$ in toluene at $60^{\circ} \mathrm{C}^{\mathrm{a}}$

\begin{tabular}{|c|c|c|c|c|c|}
\hline \multirow{2}{*}{ Run no. } & \multicolumn{2}{|c|}{ Amount of monomer feed } & \multirow{2}{*}{$\begin{array}{l}\mathrm{mol}^{\%} \text { of } \mathrm{M}_{1} \text { in } \\
\text { monomer feed }\end{array}$} & \multirow{2}{*}{ Yield $/ \%$} & \multirow{2}{*}{$\begin{array}{c}\mathrm{mol}_{\mathrm{o}} / \text { of } \mathbf{M}_{1}{ }^{\mathrm{c}} \\
\text { in polymer }\end{array}$} \\
\hline & $\mathrm{M}_{1} / \mathrm{mmol}$ & $\mathrm{M}_{2} / \mathrm{mmol}$ & & & \\
\hline 1 & 2.04 & 7.95 & 20.4 & 2.97 & 20.2 \\
\hline 2 & 2.80 & 6.87 & 29.0 & 6.42 & 26.5 \\
\hline 3 & 4.01 & 6.02 & 40.0 & 3.70 & 38.4 \\
\hline 4 & 4.84 & 5.29 & 47.8 & 2.06 & 48.4 \\
\hline 5 & 5.75 & 3.82 & 60.1 & 4.23 & 57.0 \\
\hline 6 & 9.61 & 4.43 & 68.4 & 8.45 & 69.9 \\
\hline 7 & 7.67 & 2.83 & 73.0 & 5.10 & 75.4 \\
\hline 8 & 9.20 & 2.17 & 80.9 & 4.83 & 84.2 \\
\hline
\end{tabular}

a Toluene, $3 \mathrm{~cm}^{3}$ (run 6, $4.5 \mathrm{~cm}^{3}$ ); AIBN, $0.02 \mathrm{mmol}$ (run 6, $0.03 \mathrm{mmol}$ ); polymerization time, $180 \mathrm{~min}$.

b Petroleum ether-insoluble fraction at $-50^{\circ} \mathrm{C}$.

c Determined by ${ }^{1} \mathrm{H}$ NMR spectroscopy.

Table VII. Copolymerization of $m$-EAS $\left(\mathrm{M}_{1}\right)$ with ethyl acrylate $\left(\mathrm{M}_{2}\right)$ in toluene at $60^{\circ} \mathrm{C}^{\mathrm{a}}$

\begin{tabular}{|c|c|c|c|c|c|c|}
\hline \multirow{2}{*}{ Run no. } & \multicolumn{2}{|c|}{ Amount of monomer feed } & \multirow{2}{*}{$\begin{array}{c}\mathrm{mol}^{\circ} \% \text { of } \mathrm{M}_{1} \text { in } \\
\text { monomer feed }\end{array}$} & \multirow{2}{*}{ Yield $^{\mathrm{b}} / \%$} & \multirow{2}{*}{$\mathrm{N} / \%$} & \multirow{2}{*}{$\begin{array}{c}\mathrm{mol}^{\%} \text { of } \mathrm{M}_{1} \\
\text { in polymer }\end{array}$} \\
\hline & $\mathrm{M}_{1} / \mathrm{mmol}$ & $\mathrm{M}_{2} / \mathrm{mmol}$ & & & & \\
\hline 1 & 3.87 & 15.88 & 19.6 & 4.3 & 3.68 & 36.1 \\
\hline 2 & 6.17 & 13.56 & 31.3 & 3.6 & 4.41 & 46.7 \\
\hline 3 & 8.09 & 11.06 & 42.4 & 3.6 & 4.71 & 51.6 \\
\hline 4 & 10.59 & 9.27 & 53.3 & 5.6 & 5.11 & 58.6 \\
\hline 5 & 12.56 & 7.67 & 62.1 & 4.7 & 5.18 & 59.9 \\
\hline 6 & 13.71 & 5.61 & 71.0 & 2.6 & 5.56 & 67.4 \\
\hline
\end{tabular}

a Toluene, $6 \mathrm{~cm}^{3}$; AIBN, $0.04 \mathrm{mmol}$; polymerization time, $60 \mathrm{~min}$.

b Petroleum ether-insoluble fraction at $-50^{\circ} \mathrm{C}$.

\section{DISCUSSION}

Comparison of Copolymerization Parameters for pEAS, $m-E A S$ and Other Related Styrene Derivatives

As seen in Tables VIII and IX, $p$-EAS has a larger $Q$-value and a more negative $e$-value than styrene and $p$-methylstyrene.

It is well known that $e$-values are correlated linearly with Hammett's $\sigma$-values of substituents. ${ }^{15}$ Though the $\sigma$-value of the diethylaminoethyl group $\left(\sigma_{p}=-0.14\right)^{1}$ is almost equal to that of the methyl group $\left(\sigma_{p}=-0.17\right),{ }^{16}$ copolymerization parameters for $p$-EAS and $p$-methylstyrene are markedly different from each other. Surprisingly, the $Q$ and $e$ values for $p$-EAS are rather close to that of $p$ dimethylaminostyrene, which possesses a dimethylamino group $\left(\sigma_{p}=-0.44\right)^{16}$ directly at the para- position of the aromatic ring.

Since a fairly small $r_{1} r_{2}$ value $\left(r_{1} r_{2}=0.03\right)$ was obtained in the copolymerization of $p$-EAS with MMA, the alternating nature of copolymer obtained was higher than that of copolymers of styrene with MMA $\left(r_{1} r_{2}=0.24\right)$

In contrast with $p$-EAS, the copolymerization behavior of $m$-EAS is nearly the same as that of $m$ methylstyrene.

Copolymerization of p-EAS with Acrylamide ( $A A m$ ) In the copolymerization of $p$-EAS with AAm, $p$ EAS exhibited an unexpectedly greater reactivity than AAm, and the copolymer formed was richer in $p$-EAS units than in the monomer mixture (see Table III). This may be explained if the possibility of an interaction between AAm and $p$-EAS is assumed. The diethylaminoethyl group, a weak base, in $p$ - 
Copolymerization of New Monomers Having Amino Group

Table VIII. Monomer reactivity ratios

\begin{tabular}{|c|c|c|c|c|c|c|c|}
\hline $\mathrm{M}_{1}$ & $\mathbf{M}_{2}$ & $r_{1}$ & $r_{2}$ & $r_{1} r_{2}$ & Solvent & Temp $/{ }^{\circ} \mathrm{C}$ & ref \\
\hline$p$-EAS & MMA & 0.11 & 0.26 & 0.03 & Toluene & 60 & This work \\
\hline " & Styrene & 0.59 & 1.24 & 0.73 & " & " & " \\
\hline " & AAm & 3.35 & 0.15 & 0.50 & Methanol & " & " \\
\hline$m$-EAS & MMA & 0.46 & 0.53 & 0.24 & Toluene & 60 & This work \\
\hline ", & Styrene & 1.0 & 1.0 & 1.0 & " & " & " \\
\hline " & Ethyl acrylate & 0.49 & 0.21 & 0.10 & $" \prime$ & " & $" \prime$ \\
\hline$p$-VPAB & MMA & 0.15 & 0.95 & 0.14 & Methanol & 60 & This work \\
\hline Styrene & MMA & 0.52 & 0.46 & 0.24 & Bulk & 60 & 10 \\
\hline " & AAm & 1.44 & 0.30 & 0.43 & Ethanol & 70 & 11 \\
\hline " & "' & 1.27 & 1.38 & 1.75 & Dioxane & " & " \\
\hline p-Methylstyrene & MMA & 0.44 & 0.405 & 0.18 & Bulk & 60 & 12 \\
\hline$m$-Methylstyrene & MMA & 0.49 & 0.53 & 0.26 & Bulk & 60 & 12 \\
\hline \multirow[t]{2}{*}{$p$-Dimethylaminostyrene } & MMA & 0.11 & 0.205 & 0.02 & Bulk & 60 & 12 \\
\hline & Styrene & 0.84 & 1.015 & 0.85 & " & " & " \\
\hline
\end{tabular}

Table IX. $Q$ - and $e$-values ${ }^{\mathrm{a}}$

\begin{tabular}{llll}
\hline \multicolumn{1}{c}{ Monomer (1) } & Monomer (2) & $Q_{1}$ & \multicolumn{1}{c}{$e_{1}$} \\
\hline$p$-EAS & MMA & 1.32 & -1.48 \\
$\prime \prime$ & Styrene & 1.26 & -1.36 \\
$m$-EAS & MMA & 0.85 & -0.78 \\
$\prime \prime$ & Styrene & 1.0 & -0.8 \\
$\prime \prime$ & Ethyl acrylate & 0.79 & -0.89 \\
$p$-VPAB & MMA & 0.45 & -0.99 \\
$p$-Methylstyrene & MMA & 1.08 & -0.91 \\
$m$-Methylstyrene & MMA & 0.88 & -0.76 \\
$p$-Dimethylamino- & MMA & 1.65 & -1.55 \\
styrene & Styrene & 1.36 & -1.20 \\
\hline
\end{tabular}

a $Q$ - and $e$-values were calculated from the data cited in Table VIII.

b Styrene $(Q=1.0, \quad e=-0.8) .{ }^{13}$ MMA $(Q=0.74$, $e=0.40) \cdot{ }^{13}$ Ethyl acrylate $(Q=0.42, e=0.62) .{ }^{14}$

EAS, may affect the following equilibria by a shift to the right eq 3 .

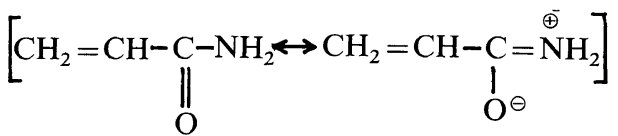

$$
\begin{aligned}
& \stackrel{\text { base }}{\rightleftarrows} \mathrm{CH}_{2}=\mathrm{CH}-\overbrace{\mathrm{OH}}^{\mathrm{C}}=\mathrm{NH}
\end{aligned}
$$

The enolate form of AAm is known to be less reactive than the keto form isomer. ${ }^{11}$
Copolymerization Behaviors of p-Vinylphenethyltriethylammonium Bromide ( $p$-VPAB)

As can be seen from Table VIII, $p$-VPAB is less reactive than $\mathrm{MMA}$, and the copolymer formed is poorer in $p$-VPAB units than in the monomer mixture. It is considered that Coulombic repulsion between $p$-VPAB and polymer chain may interfere with the approach of the charged monomer to the growing chain-end.

\section{REFERENCES}

1. T. Tsuruta, T. Narita, Y. Nitadori, and T. Irie, Makromol. Chem., 177, 3255 (1976).

2. J. Yukawa, K. Kataoka, Y. Nitadori, and T. Tsuruta, Polym. J., 11, 163 (1979).

3. K. Kataoka, T. Akaike, Y. Sakurai, and T. Tsuruta, Makromol. Chem., 179, 1121(1978).

4. K. Kataoka and T. Tsuruta, Makromol. Chem., 179, 1431 (1978).

5. K. Kataoka, N. Ohki, T. Tsuruta, N. Donkai, and H. Inagaki, Makromol. Chem., 180, 65 (1979).

6. K. Kataoka, T. Akaike, Y. Sakurai, and T. Tsuruta, Makromol. Chem., in press.

7. K. Kataoka, T. Tsuruta, T. Akaike, Y. Sakurai, I. Gonoi, S. Miyata, and K. Sakaoku, Jinkō Zōki, (Artificial Organs), 8, 296 (1979).

8. J. Yukawa, K. Kataoka, and T. Tsuruta, to be published.

9. T. Kelen and F. Tüdös, J. Macromol. Sci., Chem., A9, 1 (1975).

10. F. M. Lewis, C. Walling, W. Cummings, E. R. Briggs, and F. R. Mayo, J. Am. Chem. Soc., 70, 1519 (1948).

11. G. Saini, A. Leoni, and S. Franco, Makromol. Chem., 144, 235 (1971).

12. C. Walling, E. R. Briggs, K. B. Wolfstirm, and F. R. Mayo, J. Am. Chem. Soc., 70, 1537 (1948). 
J. Yukawa, K. Kataoka, and T. Tsuruta

13. "Copolymerization," G. E. Ham, Ed., Wiley Interscience, New York, N.Y., 1954.

14. T. Otsu, Bull. Chem. Soc. Jpn., 39, 2257 (1966).

15. J. Furukawa and T. Tsuruta, J. Polym. Sci., 36, 275
(1959).

16. "Lange's Handbook of Chemistry," J. A. Dean, Ed., McGraw-Hill, New York, N.Y., 1973, Section 3, p 128. 